\title{
James P. Stannard, James L. Cook, Jack Farr (ed.): Articular cartilage injury of the knee: basic science to surgical repair
}

\author{
Thieme Verlag, New York, Stuttgart, Delhi, Rio, 2013, 172 pp, 160 illustr., Hardcover, \\ EUR (D) 89,99, EUR (A) 92.60, CHF 126,00, ISBN: 978-1-60406-858-0
}

Pierre Kehr ${ }^{1}$

Received: 24 July 2015/ Accepted: 25 July 2015/Published online: 21 August 2015

(C) Springer-Verlag France 2015

This collective work of more than 50 collaborator authors of the USA, of Canada, of Belgium and Italy, studies the state of knowledge of the traumatic lesions of the articular cartilage of the knee. It is divided into three great parts: diagnosis and treatment planning; fundamental sciences and techniques of the repair of the cartilage; and postoperative managements. These three parts are declined in 18 chapters.

Each chapter is followed of a rich list of references, and the work comprises an index allowing a rapid access with the various entries.

This work is intended above all to the traumatologists interested by the cartilaginous lesions of the knee.

Compliance with ethical standards

Conflict of interest None.

Pierre Kehr

pierre.kehr@gmail.com

1 Strasbourg, France 